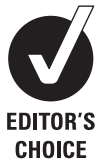

Department of Orthopaedic $\&$ Trauma Surgery, University of Dundee, Dundee, UK ${ }^{2}$ Department of Orthopaedic Surgery, Royal Infirmary of Edinburgh, Edinburgh, UK

\section{Correspondence to} Daniel Kuster, Department of Orthopaedic \& Trauma Surgery, Institute of Motion Analysis \& Research, Ninewells Hospital \& Medical School, Dundee, DD1 9SY, UK d.kuster@dundee.ac.uk

Received 24 June 2011 Accepted 22 January 2012 Published Online First 29 February 2012

\title{
Mechanisms of cervical spine injury in rugby union: a systematic review of the literature
}

\author{
Daniel Kuster, ${ }^{1}$ Alastair Gibson, ${ }^{2}$ Rami Abboud, ${ }^{1}$ Tim Drew ${ }^{1}$
}

\begin{abstract}
Background Severe cervical spine injury in rugby union (rugby) exerts a major impact on the individual who sustains the injury and on the broader society. Since the late 1970s, authors of rugby case report studies have postulated that the underlying mechanism of cervical spine injury is hyperflexion of the neck. However, this is in conflict with findings from more recent experimental studies. These have shown that it is more likely that the majority of cervical spine injuries occur due to buckling of the cervical spinal column.
\end{abstract}

Objective To investigate the primary mechanism of cervical spine injury in rugby.

Methods A comprehensive and systematic review of the literature was undertaken. Six key factors were identified and subsequently used to investigate the two principally postulated mechanisms of cervical spine injury: hyperflexion and buckling.

Results Facet dislocations, in particular bilateral facet dislocations, were identified as the most common types of cervical spine injury in rugby. Trauma occurred most often at lower cervical spinal levels, notably the C4/5 and C5/6 motion segments. Experimental studies demonstrate that bilateral facet dislocations occurring at the lower cervical spinal levels are primarily produced via buckling.

Conclusion Our analysis of key factors for cervical spine injury in rugby shows that it is unlikely that the majority of injuries occur after hyperflexion of the neck. It appears more likely that they are the result of buckling of the cervical spinal column.

\section{INTRODUCTION}

Rugby union (rugby) is a full contact team sport that has gained worldwide popularity. Unfortunately, participation in rugby carries with it a high risk of injury to the cervical spine that in severe cases results in quadriplegia, or even death.

To quantify risk, the Health and Safety Executive of the United Kingdom has defined norms for participation in certain activities. A standardised level of risk for any given activity is expressed as number of events per 100000 of an exposed population per year. ${ }^{1}$ Under this framework, the risk for sustaining cervical spine injury in rugby may be as high as 13/100 000 per year within certain countries. Although this figure falls within the 'tolerable risk' category (2-100/100 000 per year), mortality and morbidity associated with cervical spine injury exert a major impact on the individual who sustains the injury and on the broader society. ${ }^{2}$ For example, in New Zealand, a country where rugby is arguably the premier sport, the lifetime cost for a 20-year-old individual who became quadriplegic was reported to be between $\$ 2$ and 3 million in the late 1990s. ${ }^{3}$

Multiple factors contribute to cervical spine injury in rugby and anatomical and biomechanical (structural) features are relevant. Data from case reports suggest that certain distinctive anatomical features of the cervical spine such as hypermobility of the facet joints, a proportionately small vertebral body size, as well as relatively weak muscle protection constitute an increased risk for injury. ${ }^{4-6}$ Whether these are primary predisposing factors, however, is a matter for debate. It is probably more relevant that from a biomechanical perspective, the cervical spine functions essentially as a mobile column precariously located between the large mass of the head and the even larger mass of the torso. In cadaveric studies, cervical spine injury predominantly occurs when the head hits an object and the cervical spine is subsequently forced to decelerate the substantial mass of the moving torso. This facilitates buckling of the cervical spinal column as depicted in figure $1 .{ }^{78}$

In contrast to the above, rugby case report studies from the 1970s onward have postulated that most cervical spine injuries occur via a hyperflexion mechanism, primarily during scrum engagement or scrum collapse. ${ }^{3-6} 910$ Hyperflexion is characterised by an isolated flexion (single planar) force facilitating rapid forward movement of the head onto the torso thereby exceeding the normal anatomical range of $90^{\circ}$ as depicted in figure $2 .^{1112}$ This paradigm has been readily accepted despite lack of epidemiological evidence and the limitations of case studies that are based on reports from injured players. A discrepancy therefore exists between case report studies identifying hyperflexion as the primary mechanism of cervical spine injury (figure 2) and experimental cadaveric studies which have demonstrated that the majority of cervical spine injuries occur due to buckling of the vertebral column (figure 1).

The aim of this study is to establish the primary mechanism of cervical spine injury in rugby by considering the following six key factors:

- Player profile including average age.

- Player position at greatest risk.

- Phase of play that produces the majority of cervical spine injuries.

- Phase of play that produces the most severe neurological outcomes.

- Predominant type of cervical spine injury.

- Primary vertebral level of cervical spine injury. 

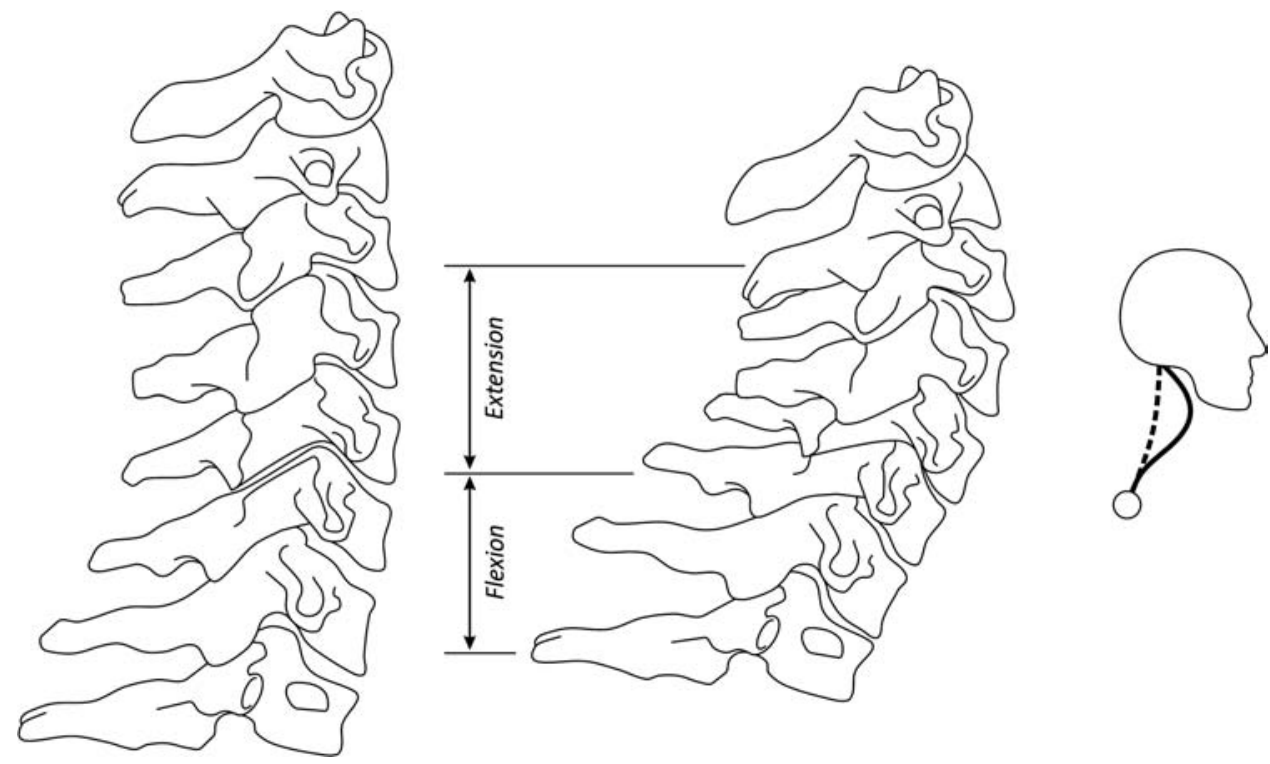

Figure 1 Experimentally observed buckling mechanism of cervical spine injury.

\section{METHODS}

\section{Data sources}

A comprehensive and systematic search of the literature was performed to identify all publications relevant to cervical spine injury in rugby union. Searches were performed on the Medline, Scopus and Sport Discus electronic databases. Terms used in the searches were identified via the Medical Subject Headings (MeSH, thesaurus). Search conditions were set to be the inclusion of the words 'spinal injuries' or 'spinal cord injuries and 'rugby' and 'cervical vertebrae' and 'biomechanics' in various combinations. No further search restrictions were applied so that an exhaustive compilation of relevant literature could be produced. One hundred and seventy-three articles met the above search criteria in Medline; Scopus returned 157 relevant articles and Sport Discus 146 articles.

The reference lists for all returned publications were examined to determine whether important references might have been missed and/or were not included in the electronic databases. The results obtained were exported into the reference management tool Endnote X4 (Thomson Reuters, 2011) and duplicates were removed.

\section{Study selection}

All case report/case series studies reporting on cervical spine injury in rugby as well as all experimental studies related to the mechanisms of cervical spine injury were included in this study. Due to the limited number of results, no further restrictions were applied.

\section{Data extraction and analysis}

Data from rugby case report/case series studies and experimental cadaveric studies were extracted using a systematic and standardised methodology that involved the detailed review of each individual article. The six key factors relating to cervical spine injury in rugby were then analysed to establish the most probable mechanism of cervical spine injury.

\section{RESULTS}

Data from 14 case reports/case series studies were available. These studies are demographically distributed as shown in table 1.

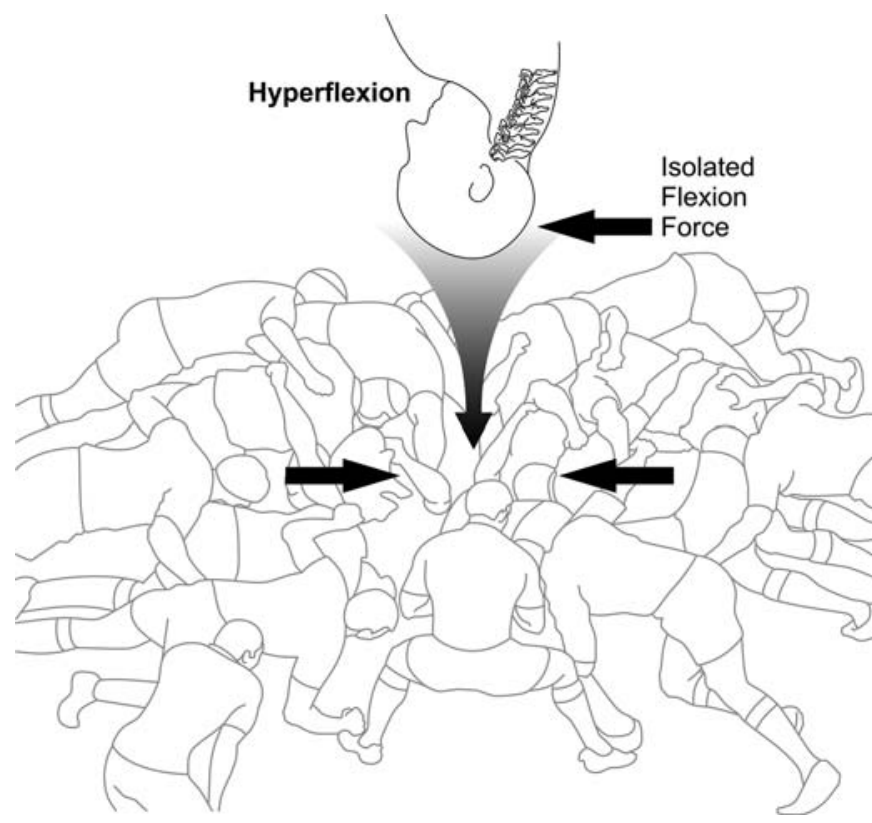

Figure 2 Postulated hyperflexion mechanism of cervical spine injury in rugby.

The key findings as shown in table 2 are summarised as follows:

The literature reports a reversal of the phases of play in which the majority of cervical spine injuries occur in rugby. Case studies undertaken prior to the year 2000 reported that cervical spine injury predominantly occurred either during scrum engagement or during scrum collapse. More recent reports, however, identify that cervical spine injury in rugby now occurs more often during open play particularly during a tackle.

Although we were able to establish the phase of play in which the majority of cervical spine injuries occur, we were unable to identify which phase of play produces more serious neurologic outcomes (based on the American Spinal Injury Association or Frankel classification systems). It therefore remains unclear whether or not a correlation between a specific phase of play and a negative neurologic outcome exists within rugby. 
Table 1 Demographic distribution of rugby case report studies

\begin{tabular}{|c|c|c|c|}
\hline Country & Year & Period of study & Authors \\
\hline UK & 2011 & 1996-2010 & McLean et al ${ }^{15}$ \\
\hline France & 2009 & 1996-2006 & Bohu et $a l^{9}$ \\
\hline Ireland & 2006 & 1995-2004 & Shelly et a ${ }^{5}$ \\
\hline England & 1988 & 1983-1987 & Silver ${ }^{13}$ \\
\hline England & 1984 & 1952-1982 & Silver ${ }^{6}$ \\
\hline Wales & 1978 & 1974-1978 & Williams and McKibbin ${ }^{10}$ \\
\hline Wales & 1987 & 1964-1984 & Williams and McKibbin ${ }^{30}$ \\
\hline South Africa & 2010 & $2003-2008$ & Dunn and van der Spruy ${ }^{16}$ \\
\hline South Africa & 2010 & 1980-2007 & Hermanus, et al ${ }^{17}$ \\
\hline Australia & 2005 & 1997-2002 & Carmody, et a/ ${ }^{18}$ \\
\hline Australia & 2003 & $1986-1996$ & Spinecare Foundation ${ }^{31}$ \\
\hline New Zealand & 1997 & 1976-1995 & Armour, et a/ ${ }^{3}$ \\
\hline New Zealand & 2000 & $1996-2000$ & Palairet and Xiong ${ }^{32}$ \\
\hline Argentina & 1999 & 1977-1997 & Secin, et al ${ }^{4}$ \\
\hline
\end{tabular}

Facet dislocations, in particular bilateral facet dislocations, were reported to be the most common types of cervical spine injury in rugby. Furthermore, trauma occurred most often within the lower cervical spine, notably at the C4/5 and C5/6 motion segments.

From the data available, player's age and position were not indicative of the primary mechanism of cervical spine injury in rugby and therefore did not exert any significant impact on this study.

Overall, the analysis of key factors for cervical spine injury in rugby shows that it is unlikely that most injuries occur via a hyperflexion mechanism. It appears more likely that the majority of cervical spine injuries are the result of buckling of the cervical spinal column.

\section{DISCUSSION}

Since the late 1970s, hyperflexion of the neck has been hypothesised to be the primary mechanism for cervical spine injury in rugby. ${ }^{3-6910}$ This mechanism seems to fit with lay mechanical intuition and has arguably become dogma within the literature. ${ }^{7}$ However, when key factors for cervical spine injury are considered, we are led to question that the primary mechanism of cervical spine injury in rugby is hyperflexion of the neck.

The hyperflexion mechanism of injury has primarily been supported by anecdotal evidence from injured players who reported hyperflexion of their neck with subsequent cervical spine injury upon scrum engagement or due to scrum collar. 46101314 However, recent case reports indicate that cervical spine injuries now occur most often during rugby tackling. ${ }^{515-18}$ The forces acting on players' necks that produce injury in a rugby tackle consist of vectors with significant compressive components and not an isolated flexion force facilitating hyperflexion of the neck. It is therefore improbable that hyperflexion of the neck is the primary mechanism of injury.

Although rare incidences of injury to the upper cervical vertebrae have been reported, ${ }^{19-21}$ including the classical example of the player who sustains a Jefferson fracture after a head on collision with the goal post, our review of the literature shows that injuries to the lower cervical motion segments are far more common in rugby. It is established from our review that the predominant types of cervical spine injury in rugby are facet dislocations, in particular bilateral facet dislocations that occur mostly at lower vertebral levels, notably the C4/5 and C5/6 motion segments.

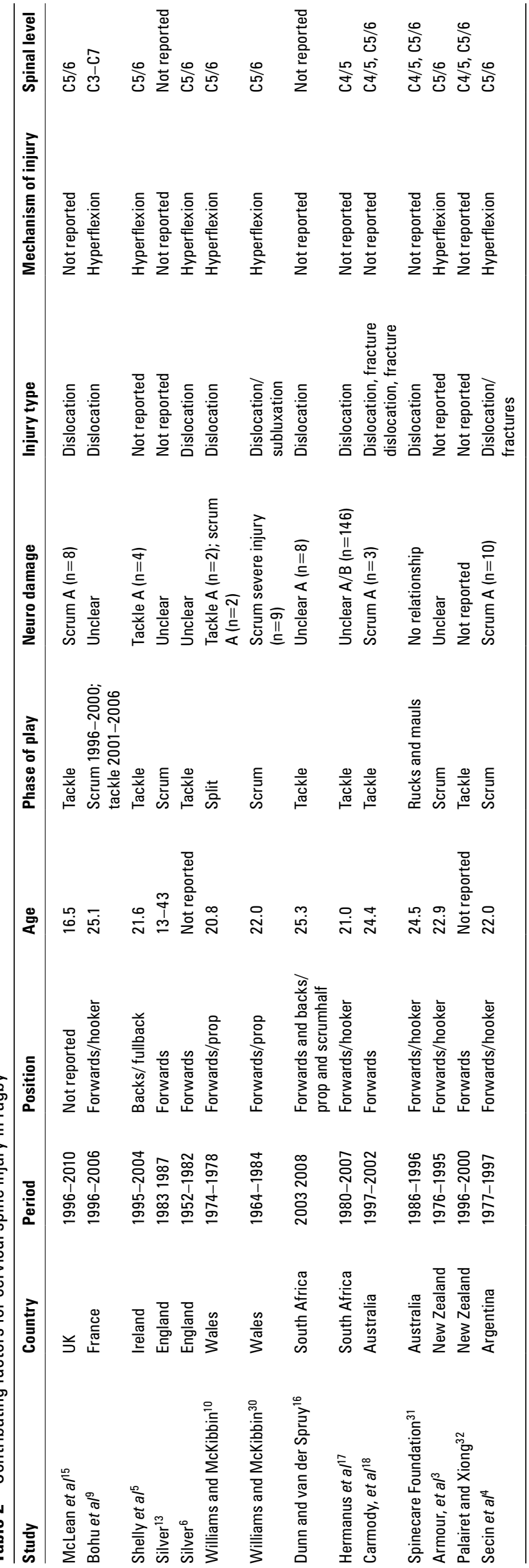


As early as the 1960s, experiments on cadavers demonstrated difficulties in producing bilateral facet dislocations solely via the application of an isolated flexion force to facilitate hyperflexion. ${ }^{22}$ In 1978, however, Bauze and Ardran were able to experimentally produce bilateral facet dislocations via the use of a compression apparatus. ${ }^{23}$ This study has been cited in an attempt to explain how hyperflexion might produce cervical spine injury in rugby. ${ }^{61314}$ However, it appears that Bauze and Ardran's compression apparatus did not produce bilateral facet dislocation via an isolated flexion force facilitating hyperflexion of the neck, but rather through force vectors with significant compressive components, similar to the axial loading forces described by Swarts et al in $2005 .^{24}$

Hyperflexion of the neck as primary mechanism of cervical spine injury becomes even more questionable when considering the findings from experimental cadaveric studies conducted at Duke University, USA, which demonstrate that cervical spine injury occurs predominantly via a buckling mechanism. Buckling of the cervical vertebral column due to force vectors with significant compressive components produces spinal injury very rapidly in between 2 and $20 \mathrm{~ms}$ (see figure 1). ${ }^{7}$ The Duke University studies demonstrated that flexion to $20^{\circ}$ did not occur until 20 to $100 \mathrm{~ms}$ had elapsed, while full hyperflexion to $90^{\circ}$ was not facilitated until 150 ms after impact, or long after injury had already occurred. The researcher's conclusion was that observable motion of the head does not correspond to the underlying mechanism of cervical spine injury.

Buckling as the primary mechanism of cervical spine injury is also in agreement with the fact that facet dislocations have been reported to occur most often within the lower cervical spine, primarily at the C4/5 and C5/6 motion segments. This fits with the findings from the Duke University studies, which show that buckling produces bilateral facet dislocations primarily at the lower cervical motion segments. ${ }^{78}$

The key factors players' ages and players' field positions did not correlate well with the predominant types of cervical spine injury in rugby, ${ }^{16}$ and were therefore not indicative of the underlying mechanism of injury. It should be recognised that the spine of a juvenile is more mobile and usually the supporting musculature is less developed. However, the implications of this observation are debatable. Investigators have established that the reflex times for muscles supporting the cervical spine are between 50 and $65 \mathrm{~ms}^{72526}$ This is substantially longer than the 2 to $20 \mathrm{~ms}$ required to produce cervical spine injury via buckling and would negate any protective effect. ${ }^{7}$

Recent studies (Allen et al personal communication) have emphasised certain benefits of age-matching and weightmatching forward players. There is now a stipulation in Scotland, by the Scottish rugby union, that all school forwards will only be certificated to play in the front row after strength testing. ${ }^{27}$ Numerous other preventive strategies, such as de-powering the scrum through player positioning and sequential engagement, have also been attempted with mixed success. ${ }^{28} 29$ The latter highlights the paramount importance of establishing the underlying mechanism of injury prior to implementing any strategy to prevent or minimise cervical spine injuries in rugby. The underlying principle of effective injury prevention was clearly stated by Winkelstein and Myers: clearly, if we are to become more effective in preventing cervical spine injuries, a cogent understanding of how they occur must first be achieved. 8

\section{CONCLUSION}

Our analysis of key factors for cervical spine injury in rugby does not support hyperflexion of the neck as the principle mechanism of cervical spine injury in rugby. It appears more likely that the majority of cervical spine injuries occur due to buckling of the cervical vertebral column, facilitated in less than $20 \mathrm{~ms}$ after impact. Direct observation of head movement probably does not reflect the relative motion of the involved vertebral segments. Further experimental studies will be valuable in confirming our findings.

Contributors DK, JG and TD extracted the data and collated the information. RA supervised the preparation of this manuscript.

Acknowledgements The authors would like to thank Professors Roger Nightingale and Barry Myers of Duke University for their contribution to this research.

Funding DK is a MBPhD student funded by the University of Dundee.

Competing interests None.

Provenance and peer review Not commissioned; externally peer reviewed.

\section{REFERENCES}

1. Fuller CW. Catastrophic injury in rugby union: is the level of risk acceptable? Sports Med 2008;38:975-86.

2. Quarrie KL, Cantu RC, Chalmers DJ. Rugby union injuries to the cervical spine and spinal cord. Sports Med 2002;32:633-53.

3. Armour KS, Clatworthy BJ, Bean AR, et al. Spinal injuries in New Zealand rugby and rugby league-a twenty year survey. N Z Med J 1997;110:462-5.

4. Secin FP, Poggi EJ, Luzuriaga F, et al. Disabling injuries of the cervical spine in Argentine rugby over the last 20 years. Br J Sports Med 1999;33:33-6.

5. Shelly MJ, Butler JS, Timlin M, et al. Spinal injuries in Irish rugby: a ten-year review. J Bone Joint Surg Br 2006;88:771-5.

6. Silver JR. Injuries of the spine sustained in rugby. Br Med J (Clin Res Ed) 1984;288:37-43.

7. Nightingale RW, McElhaney JH, Richardson WJ, et al. Experimental impact injury to the cervical spine: relating motion of the head and the mechanism of injury. J Bone Joint Surg Am 1996;78:412-21.

8. Winkelstein BA, Myers BS. The biomechanics of cervical spine injury and implications for injury prevention. Med Sci Sports Exerc 1997;29:S246-55.

9. Bohu Y, Julia M, Bagate C, et al. Declining incidence of catastrophic cervical spine injuries in French rugby: 1996-2006. Am J Sports Med 2009;37:319-23.

10. Williams JP, McKibbin B. Cervical spine injuries in Rugby Union football. Br Med J 1978;2:1747.

11. McElhaney JH. In: Nahum AM, ed. Accidental Injury: Biomechanics and Prevention. New York: Springer 2002:324-73.

12. Noakes TD, du Plessis M. In: Van Shaik, ed. Rugby Without Risk. Van Schaik Uitgewers, Pretoria: 1996:121-52.

13. Silver JR, Gill S. Injuries of the spine sustained during rugby. Sports Med 1988:5:328-34.

14. Silver JR. Injuries of the spine sustained during rugby. $B r J$ Sports Med 1992;26:253-8.

15. McLean J, Hutchinson JD. Serious Neck Injuries in U19 Rugby Union Players. Br J Sports Med Published Online First: 14 December 2011 doi:10.1136/bjsports2011-090183.

16. Dunn RN, van der Spuy D. Rugby and cervical spine injuries - has anything changed? A 5-year review in the Western Cape. S Afr Med J 2010;100:235-8.

17. Hermanus FJ, Draper CE, Noakes TD. Spinal cord injuries in South African Rugby Union (1980 - 2007). S Afr Med J 2010;100:230-4.

18. Carmody DJ, Taylor TK, Parker DA, et al. Spinal cord injuries in Australian footballers 1997-2002. Med J Aust 2005;182:561-4.

19. Scher AT. Rugby injuries of the upper cervical spine. Case reports. S Afr Med J 1983;64:456-8

20. Scherping SC, Kang JD. Fractures and dislocations of the upper cervical spine. In: Emery SE, Boden SD, eds. Surgery of the Cervical Spine. Elsevier Science, Philadelphia, 2003:157-82.

21. Jefferson G. Fracture of the atlas vertebra. Br J Surg 1920;7:407-22.

22. Roaf R. A study of the mechanics of spinal injuries. J Bone Joint Surg 1960;42B:810-23.

23. Bauze RJ, Ardran GM. Experimental production of forward dislocation in the human cervical spine. J Bone Joint Surg Br 1978;60-B:239-45.

24. Swartz EE, Floyd RT, Cendoma M. Cervical spine functional anatomy and the biomechanics of injury due to compressive loading. J Athl Train 2005; $40: 155-61$. 


\section{Review}

25. Foust DR, Chaffin DB, Snyder RG, et al. Biomechanical Properties of the Human Neck in Lateral Flexion. Warrendale, Pennsylvania, USA: Society of Automotive Engineers 1975.

26. Foust DR, Chafin DB, Snyder RG, et al. Cervical Range of Motion and Dynamic Response and Strength of Cervical Muscles. Warrendale, Pennsylvania, USA: Society of Automotive Engineers, 1971

27. Ferguson $\mathbf{D}$. Strength test failures raise concerns about the furure of youth rugby. The Scotsman 2010.

28. Quarrie KL, Gianotti SM, Hopkins WG, et al. Effect of nationwide injury prevention programme on serious spinal injuries in New Zealand rugby union: ecological study. BMJ 2007;334:1150.
29. Milburn PD, 0'Shea BP. The sequential scrum engagement: a biomechanical analysis. Aust J Sci Med Sport 1994;26:32-5.

30. Williams $\mathbf{P}$, McKibbin B. Unstable cervical spine injuries in rugby-a 20-year review. Injury 1987;18:329-32.

31. Spine Care Foundation. Spinal cord injuries in Australian footballers. ANZ J Surg 2003; 73:493-9.

32. Palairet $\mathbf{T}$, Xiong $X$. A study of rugby and rugby league spinal injuries in New Zealand between 1996 to 2000. Proceedings at the Spinal Network Conference, September, 2000 